American Journal of Pharmacology and Toxicology 3 (3): 212-218, 2008

ISSN 1557-4962

(C) 2008 Science Publications

\title{
Analysis of Certain Tetracyclines and Oxytetracyclines through Charge Transfer Complexation
}

\author{
Khairi M.S. Fahelelbom \\ College of Pharmacy, AL-Ain University of Science and Technology, \\ Al-Ain 64141, United Arab Emirates
}

\begin{abstract}
Problem statement: Several studies were carried out to develop and validate a simple, rapid and accurate spectrophotometric method for the analysis of tetracycline (TC) and oxytetracycline (OTC) in the pure form and in pharmaceutical dosage forms, despite the varieties of these analytical techniques, the literature revealed that no spectrophotometric method for determination of tetracycline and oxytetracycline using charge transfer complexation with chloranilic acid has been reported. Approach: In the present study, a new and simple spectrophotometric method is described for the determinations of tetracycline (TC) and oxytetracycline (OTC), the method is based on the molecular interaction between the tetracyclines and Chloranilic Acid (CA), to form a charge-transfer complex in which the drugs acts as n-donor and chloranilic acid as $\pi$-acceptor in acetonitrile. The spectra, various experimental parameters for the reaction, the stability of the complex and the validty of the method were investigated. Results: The formed complex was found to absorb maximally at 540nm, Beer's law is obeyed in the concentration ranges $2.5-30 \mu \mathrm{g} \mathrm{mL}^{-1}$ and $5.0-40 \mu \mathrm{g} \mathrm{mL}^{-1}$ for TC and OTC, respectively. The limits of detection $(\mathrm{S} / \mathrm{N}=3)$ were $0.40 \mu \mathrm{g} \mathrm{m}^{-1}$ for tetracycline and $0.50 \mu \mathrm{g} \mathrm{mL}^{-1}$ for oxytetracycline. The molar ratio was found to be approximately $1: 1$, confirming that one molecule of tetracycline or oxytetracycline combines with one molecule of chloranilic acid. Conclusions and Recommendations: The proposed method was found to be rapid, accurate and sensitive and may be applied for estimation of named drugs in pharmaceutical dosage forms without interferences from the common additives encountered. Percentage recoveries ranged from $99.17 \% \pm 0.95-100.38 \% \pm 0.82$. From the statistical analysis of the obtained results one can conclude that no significant difference between the proposed method and other official methods as evident from the $t$-test and variance ratio. These findings recommend the utility of the proposed method in the quality control analysis of TC and OTC in the pure form and pharmaceutical dosage forms.
\end{abstract}

Key words: Tetracycline, oxytetracycline, chloranilic acid, charge transfer complexation

\section{INTRODUCTION}

Tetracyclines possess a wide range of antimicrobial activity against gram-positive and gram-negative bacteria; they have been used not only in human medicine for the treatment of infectious disease but also as an additive in animal feed to promote growth. Although the development of new antimicrobial agents that are more effective for specific infections and less toxic have declined the indications for their use, tetracyclines are still used widely in both human and veterinary medicine ${ }^{[1]}$.

Both the British Pharmacopoeia ${ }^{[2]}$ and the United States Pharmacopoeia ${ }^{[3]}$ recommend the use of HPLC for the bulk drugs and their formulations. The literature is enriched with various methods for the determination of the drugs in pharmaceutical preparations and biological fluids, viz fluorometry ${ }^{[4,7]}$, HPLC $^{[8,14]}$, Flow-
Injection Analysis (FIA)-chemiluminescence's ${ }^{[15,16]}$ and FIA/amperometric detection ${ }^{[17]}$, in addition to electrochemical methods ${ }^{[18,20]}$.

UV-Visible spectrophotometry is still considered to be as a convenient and low cost method for the determination of pharmaceuticals in bulk and dosage forms. Several spectrophotometric and colorimetric methods have been reported for the determination of tetracyclines in bulk material and dosage forms based on their reaction with different reagents such as ammonium vanadate ${ }^{[21]}$, cupric chloride ${ }^{[22]}$, Diphenyl-1Picrylhydrazyl (DPH) ${ }^{[23]}$ and sodium molybdate ${ }^{[24]}$.

The charge transfer reactions of certain $\Pi$ acceptors have been utilized successfully in pharmaceutical analysis. Chloranilic acid is a $\tau \tau$ acceptor used for the analysis of certain penicillines $^{[25,26]}$, cephalosporines ${ }^{[27,28]}$, imipramine ${ }^{[29]}$, antimalarials $^{[30]}$, antifungal ${ }^{[31]}$ and propranolol ${ }^{[32]}$. A 
review of literature revealed that no spectrophotometric method for determination of tetracycline and oxytetracycline through charge transfer complexation with chloranilic acid has been reported. This led us to study the reaction of chloranilic acid with those drugs in an attempt to develop a simple and reliable spectrophotometric method for their determination either pure form or in formulations.

\section{MATERIALS AND METHODS}

Apparatus: A Beckman model DU 52 UV-Visible spectrophotometer, with $1-\mathrm{cm}$ quartz cell was used to measure the absorbance values and A Thermo Orion $\mathrm{pH}$ meter-model 210 was used in measurement of $\mathrm{pH}$ values.

Materials and reagents: Double-distilled water and analytical grade reagents were used to prepare all solutions.

Acetonitrile and methanol were obtained from BDH; Poole, England, chloranilic acid (Merck, Darmstadt, Germany) was prepared as $0.2 \% \mathrm{w} / \mathrm{v}$ solution in acetonitrile.

Pharmaceutical grade tetracycline and oxytetracycline were obtained from El-Nasser Chemical Co., Egypt and their standard solutions were prepared as $0.05 \% \mathrm{w} / \mathrm{v}$ in methanol, all solutions containing TC and OTC were protected from direct sunlight and artificial light throughout the analysis, because of the photosensitivity of tetracyclines to light.

Different dosage forms containing tetracycline and oxytetracycline were obtained commercially from different sources.

Borate buffer $0.05 \mathrm{M}(\mathrm{pH} 9.0)$ was prepared by dissolving $4.7675 \mathrm{~g}$ of borax in distilled water and completed into a $250 \mathrm{~mL}$.

Acetate buffer $\mathrm{pH} 3.0$ was prepared by dissolving $4 \mathrm{~g}$ of anhydrous sodium acetate in $840 \mathrm{~mL}$ of water. Sufficient amount of glacial acetic acid (about $155 \mathrm{~mL}$ ) was added to adjust $\mathrm{pH}$. The solution was transferred into a $1000 \mathrm{~mL}$ volumetric flask \& diluted to $1000 \mathrm{~mL}$ with distilled water.

Calibration curves: Serial volumes of standard solutions ranging from $0.2-1.0 \mathrm{~mL}$ (TC) or 0.25-1.25 (OTC) were transferred into a $10 \mathrm{~mL}$ volumetric flask, followed by addition of $2 \mathrm{~mL}$ of borate buffer then $1 \mathrm{~mL}$ of $0.2 \%$ chloranilic acid and the volume was brought to the volume with acetonitrile and the absorbance was measured at $540 \mathrm{~nm}$ against a reagent blank prepared simultaneously. The absorbance is plotted against final concentration to get the calibration graphs. Alternatively, the corresponding regression equations were derived.

Procedures for tetracycline and oxytetracycline raw materials: An accurately weighed amount $(0.05 \mathrm{~g})$ of each of TC and OTC raw material was dissolved in $100 \mathrm{~mL}$ of methanol. Two $\mathrm{mL}$ of these solutions were transferred into $10 \mathrm{~mL}$ volumetric flask, followed by addition of $2 \mathrm{~mL}$ of borate buffer and $1 \mathrm{~mL}$ of chloranilic acid, the solutions were diluted into $10 \mathrm{~mL}$ acetonitrile and the absorbance values were measured against a reagent blank at $540 \mathrm{~nm}$. The $\%$ purity was calculated either from the calibration graph or using the corresponding regression equation.

Procedures for capsules: From a quantity of the mixed contents of 20 capsules of TC or OTC, an accurately weighed quantity equivalent to $0.5 \mathrm{~g}$ of drug was transferred into $100 \mathrm{~mL}$ volumetric flask and dissolved in $50 \mathrm{~mL}$ of methanol. The contents were shaken and then completed to volume with methanol. After the solutions were filtered, $10 \mathrm{~mL}$ of the filtrate were completed to $100 \mathrm{~mL}$ with methanol, in order to get $0.05 \% \mathrm{w} / \mathrm{v}$ solution and then the procedure was completed as described under raw material. The concentration was determined using the corresponding regression equation.

Procedures for oxytetracycline ampoules: The volumes of 10 ampoules were transferred to a measuring cylinder. An accurately measured volume containing $0.5 \mathrm{~g}$ of oxytetracycline was transferred to $100 \mathrm{~mL}$ volumetric flask, followed by the addition of $50 \mathrm{~mL}$ of methanol, the contents were shaken and completed to volume with methanol. After filtering the solution if necessary, $10 \mathrm{~mL}$ of the filtrate were completed to $100 \mathrm{~mL}$ with methanol and the procedure was completed as described under raw material and the derived regression equation was used for the determination of the concentration.

\section{RESULTS}

The absorption spectrum of p-chloranilic acid in acetonitrile exhibits an absorption band at $390 \mathrm{~nm}$, the addition of TC and OTC to this solution produces an immediate change of the yellowish-pink color of chloranilic acid into violet color forming a new characteristic absorption band at $540 \mathrm{~nm}$ (Fig. 1). The addition of $c$ hloranilic acid to tetracycline having a lone pair of electrons results in the formation of a charge transfer complex of the $n-\pi$ type. This compound is supposed to be an intermediate molecular association complex, which produces the corresponding radical ions in acetonitrile and an absorption band at $540 \mathrm{~nm}$. 
Am. J. Pharm. \& Toxicol., 3 (3): 212-218, 2008

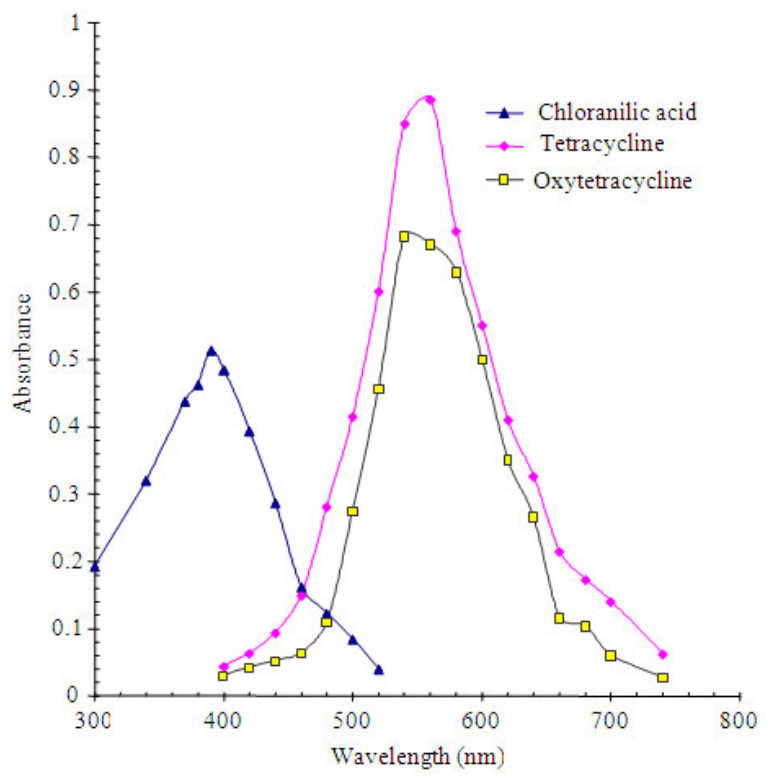

Fig. 1: Absorption spectra of the products of tetracycline $\left(30 \mu \mathrm{g} \quad \mathrm{mL}^{-1}\right)$ oxytetracycline $\left(15 \mu \mathrm{g} \mathrm{mL}^{-1}\right)$ and $\mathrm{p}$ chloranilic acid

The color intensity reaches its maximum at room temperature and remains stable up to $20 \mathrm{~min}$.

The effect of the volume of chloranilic acid on the formation of the charge transfer complex was studied by taking $0.5 \mathrm{ml}$ of $0.05 \%$ tetracycline and oxytetracycline respectively, followed by addition of different volumes of $0.2 \%$ p-chloranilic acid in acetonitrile; the purple color was formed instantly. After the dilution of the reaction mixture to $5 \mathrm{~mL}$ with acetonitrile, the absorbencies were recorded. The results show that the highest absorbance was obtained with $1 \mathrm{~mL}$ p-chloranilic acid solution (Fig. 2).

Under the optimum experimental conditions, the absorbance responses were linear to the concentration in relation to concentration of $\mathrm{TC}$ over the range 2.5-30 $\mu \mathrm{g} \mathrm{mL}^{-1}$ and OTC over the range 5.0-40 $\mu \mathrm{g}$ $\mathrm{mL}^{-1}$. Beer's law range and detection limits are given in Table 1. Regression analysis of the data indicates that the values of the intercepts were small; the values were 0.0076 for TC and 0.0095 for OTC and the correlation coefficient values were 0.9997 and 0.9989 for TC and OTC respectively.

Table 2, shows the accuracy and precision of the method as described by; the values for the range, percent error, Standard Deviations (SD) and the Relative Standard Deviation (RSD \%) for TC and OTC determined by the proposed method.
Table 1: Analytical parameters for the charge transfer complexes of TC and OTC with p-chloranilic acid

\begin{tabular}{lll}
\hline Parameter & TC & OTC \\
\hline Beer's law limits $\mu \mathrm{g} \mathrm{mL}^{-1}$ & $2.5-20$ & $5-25$ \\
Limit of detection $\mu \mathrm{g} \mathrm{mL}^{-1}$ & 0.40 & 0.50 \\
Linear regression results* & & \\
Intercept a & 0.0076 & 0.0095 \\
Slope b & 0.0296 & 0.0433 \\
Correlation coefficient & 0.9997 & 0.9989 \\
\hline$* \cdot \mathrm{Y}=\mathrm{a}+\mathrm{bX}$ & &
\end{tabular}

$*: \mathrm{Y}=\mathrm{a}+\mathrm{bX}$

where, $\mathrm{Y}$ is the absorbance for the concentration $\mathrm{X}$ in $\mu \mathrm{g} \mathrm{mL} \mathrm{L}^{-1}$

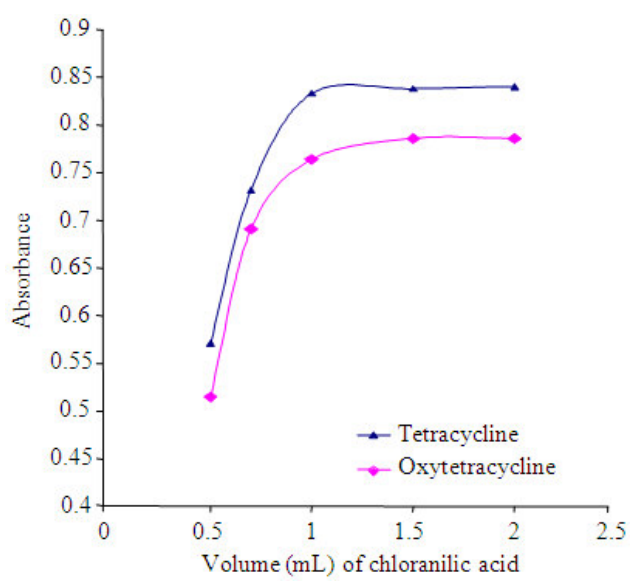

Fig. 2: The effect of chloranilic acid volume on the charge complex reaction with tetracyclines

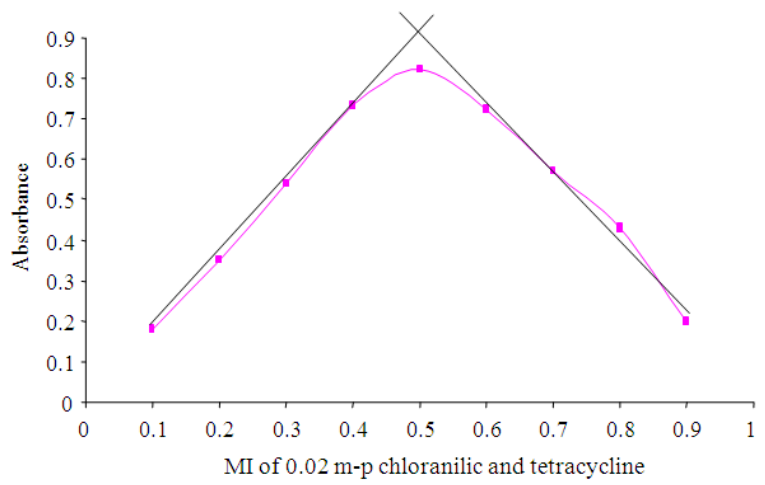

Fig. 3: The continuous variation method for the stoichiometry of the reaction of chloranilic acid and tetracycline

The results of the analysis of tetracycline and oxytetracycline capsules using the proposed and USP official methods were described in Table 3.

The continuous variation method for the stoichiometry of the reaction of p-chloranilic acid with TC and OTC are shown in Fig. 3 and 4. 
Am. J. Pharm. \& Toxicol., 3 (3): 212-218, 2008

Table 2: Accuracy and precision evaluation parameters for the proposed method

\begin{tabular}{|c|c|c|c|c|c|c|c|}
\hline \multirow[b]{2}{*}{ Drug } & \multirow[b]{2}{*}{ Taken, $\mu \mathrm{g} \mathrm{mL}^{-1}$} & \multirow[b]{2}{*}{ Found, $\mu \mathrm{g} \mathrm{mL}^{-1}$} & \multirow[b]{2}{*}{ Range, $\mu \mathrm{g} \mathrm{mL}^{-1}$} & \multicolumn{4}{|c|}{ Concentration } \\
\hline & & & & Error \% & $\mathrm{S}, \mu \mathrm{g} \mathrm{mL} L^{-1}$ & $\operatorname{RSD} \%(\mathrm{n}=7)$ & $X-\mu$ \\
\hline \multirow[t]{3}{*}{$\overline{\mathrm{TC}}$} & 5 & 5.04 & 0.16 & 1 & 0.06 & 1.19 & 0.04 \\
\hline & 10 & 10.1 & 0.24 & 0.9 & 0.06 & 0.55 & 0.1 \\
\hline & 15 & 15.11 & 0.22 & 0.73 & 0.08 & 0.53 & 0.11 \\
\hline \multirow[t]{3}{*}{ OTC } & 5 & 4.94 & 0.18 & 1.2 & 0.06 & 1.28 & 0.06 \\
\hline & 10 & 9.99 & 0.25 & 0.1 & 0.09 & 0.9 & 0.01 \\
\hline & 15 & 14.96 & 0.27 & 0.26 & 0.09 & 0.6 & 0.04 \\
\hline
\end{tabular}

Table 3: Analysis of tetracycline and oxytetracycline capsules using the proposed and USP official methods

\begin{tabular}{|c|c|c|}
\hline Dosage form & $\begin{array}{l}\text { Proposed method* } \\
\text { \% Recovery }\end{array}$ & $\begin{array}{l}\text { USP official method** } \\
\text { \% Recovery (Ref.) }\end{array}$ \\
\hline Tetraco® capsules & $99.65 \pm 0.78$ & $98.96 \pm 0.85$ \\
\hline $\begin{array}{l}250 \mathrm{mg} \text { tetracycline/ } \\
\text { capsule }\end{array}$ & $\mathrm{t}=0.845(3.306)^{* * *}$ & $\mathrm{~F}=1.178(6.39 . . * * *$ \\
\hline $\begin{array}{l}\text { Tetracycline capsule } \\
\text { (Julphar-UAE) }\end{array}$ & $100.38 \pm 0.82$ & $100.20 \pm 0.95$ \\
\hline $\begin{array}{l}250 \mathrm{mg} \text { tetracycline/ } \\
\text { capsules }\end{array}$ & $\mathrm{t}=0.102(3.306)$ & $\mathrm{F}=1.342(6.39)$ \\
\hline $\begin{array}{l}\text { Oxytetracycline capsules } \\
\text { (Julphar-UAE) }\end{array}$ & $99.17 \pm 0.95$ & $99.51 \pm 1.13$ \\
\hline $\begin{array}{l}250 \mathrm{mg} \text { oxytetracycline/ } \\
\text { capsules }\end{array}$ & $t=0.165(3.306)$ & $\mathrm{F}=1.415(6.39)$ \\
\hline $\begin{array}{l}\text { Terramycin }{ }^{\circledR} \text { Injection } \\
250 \mathrm{mg} \text { oxytetracycline } \\
\text { per } 2 \mathrm{~mL}\end{array}$ & $\begin{array}{l}99.23 \pm 1.25 \\
t=0.711(3.306)\end{array}$ & $\begin{array}{l}101.10 \pm 1.16 \\
\mathrm{~F}=1.161(6.39)\end{array}$ \\
\hline
\end{tabular}

*: Average of at least three triplicate determinations calculated relative to nominal content; **: The United State Pharmacopoeia ${ }^{[3]}$; ***: Values in parentheses are theoretical values of $\mathrm{t}$ and $\mathrm{F}$ at $\mathrm{p}=0.5$

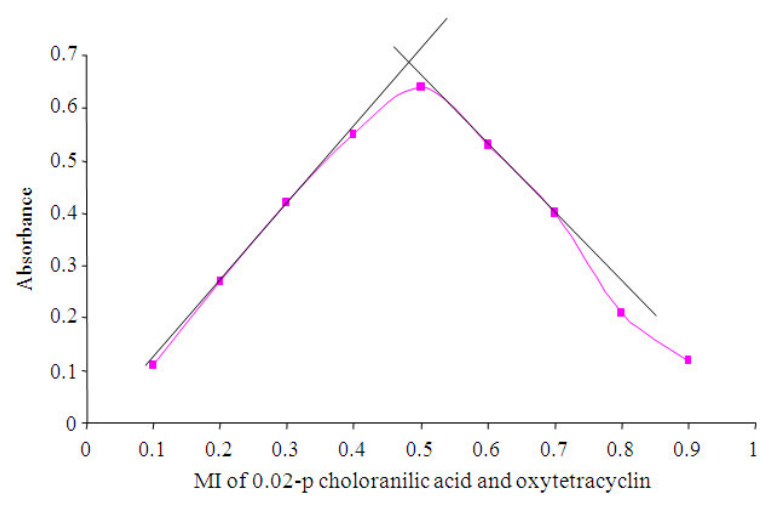

Fig. 4: The continuous variation method for the stoichiometry of the reaction of chloranilic acid and oxytetracycline

\section{DISCUSSION}

It has been reported that $\mathrm{p}$-chloranilic acid exists in three forms ${ }^{[33]}$, the neutral yellow $\mathrm{H}_{2} \mathrm{~A}$ at very low $\mathrm{pH}$ : the dark violet $\mathrm{HA}^{-}$which is stable at $\mathrm{pH} 2$; and the pale-violet $\mathrm{A}_{2}$ is stable at high $\mathrm{pH}$ value. In order to study the suitable conditions for the complexation to occur, the procedure was performed using two different media; $\mathrm{pH} 3.0$ (using acetate buffer) and $\mathrm{pH} 9$ (using borate buffer). At $\mathrm{pH} 3.0$ no complexation has occurred, while at $\mathrm{pH} 9$ complexation and the formation of purple color was immediately noticed.

For the complexation to occur, free electrons are required, but at low $\mathrm{pH}$ medium these free electrons, are involved in protonation reactions in acidic media hence there will be no free electrons to form a complex with chloranilic acid. At high basic medium, $\mathrm{pH} 9$ the electrons of dimethylamine group get involved in the complexation reaction with the chloranilic acid (Scheme 1).

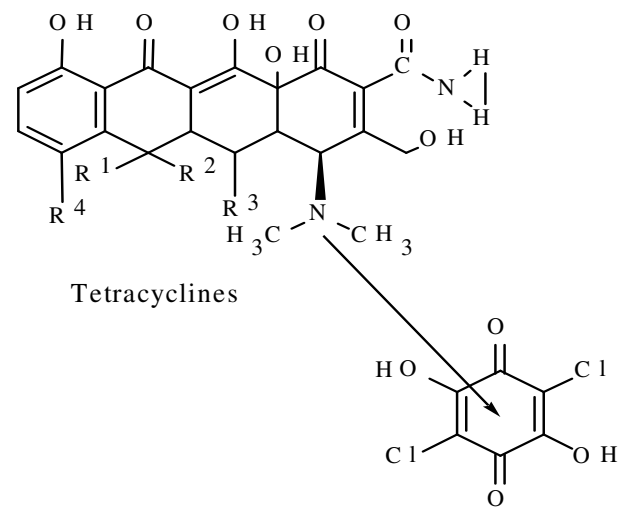

Analytical performance: The correlation coefficient values for TC and OTC respectively, indicating a perfect linearity between absorbance and concentration of the drugs within the Beer's law studied limits.

Accuracy and precision: The accuracy of the method was established by performing seven replicate analyses on solutions containing three different amounts (within the Beer's law limits) for TC and OTC and calculating the percentage error. The precision of the method was achieved by calculating the Relative Standard Deviation (RSD) for seven determinations at each level. It is clear from the results that, the values obtained for SD, RSD and \% Error, indicate the higher accuracy and precision for the proposed method.

Analysis of TC and OTC in pharmaceutical formulations: The proposed method, when compared 
to the official ones, offers advantages with regards to, accuracy and precision ${ }^{[37]}$. The calculated student's $t$ test and Variance ratio $F$ test were less than the respective tabulated ones at $\mathrm{p}=0.05$, indicating that the results obtained by the proposed method is in good agreement with those obtained by the official method. Regarding the sensitivity the proposed procedure is as sensitive as the official ones. However the proposed method is simpler and rapid. Moreover results of the determination of in different dosage forms by the proposed method indicate that ingredients other than tetracyclines such as additives, stabilizers and antioxidants of tablets and ampoules did not interfere with the recommended method.

The Molar reactivity of chloranilic acid with TC and OTC The molar reactivity of chloranilic acid with both drugs in the reaction product was determined by the molar ratio method $^{[35]}$ limiting logarithmic method ${ }^{[36]}$ and continuous variation method. The molar ratio was found to be approximately $1: 1$, confirming that one molecule of tetracycline or oxytetracycline combines with one molecule of chloranilic acid. Figure 3 and 4 Show continuous variation method for TC and OTC respectively, other two methods gave the same results. The formation constant of the reaction product $\mathrm{K}_{\mathrm{f}}$ was calculated adopting the following formula ${ }^{[34]}$ :

$$
\mathrm{K}_{\mathrm{f}}=\mathrm{A} / \mathrm{Am} /[1-\mathrm{A} / \mathrm{Am})^{\mathrm{n}+1} C^{\mathrm{n}} \mathrm{n}
$$

Where:

$\mathrm{A}=$ Maximum absorbance

Am $=$ The absorbance corresponding to intersection of the two tangents of the curve in Fig. 3 and 4

$\mathrm{C}=$ The concentration corresponding to maximum absorbance

$\mathrm{N}=$ The amount of the drug in reaction product. Using this equation

$\mathrm{K}_{\mathrm{f}} \quad=$ Found to be equal to 2307 and 2883 for TC and OTC respectively

The Gibbs free energy of the reaction was also calculated adopting the equation ${ }^{[34]}$ :

$$
\Delta \mathrm{G}=-2.303 \mathrm{RT} \log \mathrm{K}_{\mathrm{f}}
$$

Where:

$\Delta \mathrm{G}=$ Gibbs free energy of the reaction

$\mathrm{R}=$ The universal gas constant

$\mathrm{T}=$ The absolute temperature

$\mathrm{K}_{\mathrm{f}}=$ Formation constant of the reaction

The value of $\Delta \mathrm{G}$ is found to be-742.7 and$745 \mathrm{Kcal} \mathrm{mole}^{-1}$, for TC and OTC respectively. The negative value of $\Delta G$ point out to the spontaneous nature of the reaction.

\section{CONCLUSION}

From the foregoing discussion charge transfer technique using p-chloranilic acid succeeded for the determination of tetracycline and oxytetracycline in pure form and in pharmaceutical preparations. Pharmaceutical additives did not interfere with the assay.

\section{REFERENCES}

1. Williams, D. and L. Thomas, 2002. Foye's Principles of Medicinal Chemistry. 5th Edn., Lippincott Williams and Wilkins, Philadelphia, USA., ISBN: 0683307371, pp:1114.

2. The British Pharmacopoeia, 2005 Vol. II. Her Majesty Stationary Office, London, pp: 1490-1494, 1932-1934.

3. The United Sates Pharmacopeia, 2004. The US Pharmaceutical Convention, N F 27, Rockville, pp: 1386-1392, 1800-1807.

4. Fernandez-Gonzalez, R., M.S. Garcia-Falcon and J. Simal-Gandra, 2002. Quantitative analysis for oxytetracycline in medicated premixes and feeds by second-derivative synchronous spectrofluorimetry. Anal. Chim. Acta, 455: 143-148. DOI: 10.1016/S0003-2670(01)01590-2

5. Gala, B., A. Gomez-Hens and D. Perez-Bendito, 1997. Simultaneous determination of ampicillin and tetracycline in milk by using a stopped-flow/Tformat spectrofluorimeter. Talanta, 44: 188-1889. DOI: 10.1016/S0039-9140(97)00084-2

6. Savage, A.L., S.H. Sarigjo and J. Baird, 1998. Flow injection of tetracycline. Anal. Chim. Acta, 375: 1-4. DOI: 10.1016/j.aca.2004.11.013

7. Goicoechen, H.C. and A.C. Olivieri, 1999. Enhanced synchronous Spectrofluorometric determination of tetracycline in blood serum by chemometric analysis. Comparison of partial least squares and hybrid linear analysis calibration. Anal. Chem., 71: 4361-4368. DOI: 10.1021/ac990374e

8. Cherlet, M., M. Schelkens, S. Croublcs and P. De Backer, 2003. Quantitative multi-residue analysis of tetracyclines and their 4-epimers in pig tissues by high-performance liquid chromatography combined with positive-ion electrospray ionization mass spectrometry. Anal. Chim. Acta, 492: 199-213. DOI: 10.1016/S00032670(03)00341-6 
9. Delepee, R., D. Maume, B. Le Bizee and H. Pouliquen 2000. Preliminary assays to elucidate the structure of oxytetracycline degradation products in sediments: Determination of natural tetracyclines by high-performance liquid chromatography-fast atom bombardment mass spectrometry. J. Chromatogr. B., 748: 369-381. DOI: 10.1016/S0378-4347(00)00355-8

10. Zhu, J., D.D. Snow, D.A. Cassada and J. Monson, 2001. Analysis of oxytetracycline, tetracycline and chlortetracycline in water using solid-phase extraction and liquid chromatography-tandem mass spectrometry. J. Chromatogr. A., 928: 177-186. DOI: 10.1016/S0021-9673(01)01139-6

11. Monser, L. and F. Darghouth, 2002. Rapid liquid chromatographic method for simultaneous determination of tetracyclines antibiotics and 6Epi-doxycycline in pharmaceutical products using porous graphitic carbon column. J. Pharm. Biomed. Anal., 23: 353-362. DOI: 10.1016/S07317085(00)00329-0

12. Cinquina, A.L., F. Longo, G. Anastasi, L. Giannetti and R. Cozzani, 2003. Validation of a highperformance liquid chromatography method for the determination of oxytetracycline, tetracycline, chlortetracycline and doxycycline in bovine milk and muscle. J. Chromatogr. A., 987: 227-233. DOI: 10.1016/S0021-9673(02)01446-2

13. Delepee, R. and H. Pouliquen, 2003. Ion-paired solid phase extraction as a sample preparation strategy for the high-performance liquid chromatographic determination of oxytetracycline in the bryophyte Fontinalis antipyretica. Anal. Chim. Acta, 475: 117-123. DOI: 10.1016/S00032670(02)01222-9

14. Charoenraks, T., S., Chuanuwatanakul, K. Honda, Y. Yamaguchi and O. Chailapakul, 2005. Analysis of tetracycline antibiotics using HPLC with pulsed amperometric detection. Ana. Sci., 21: 241-245. DOI: 10.2116/analsci.21.241

15. Zheng, X., Y. Mei and Z. Zhang, 2001. Flowinjection chemiluminescence determination of tetracyclines with in situ electrogenerated bromine as the oxidant. Anal. Chim. Acta, 440: 143-149. DOI: 10.1016/S0003-2670(01)01050-9

16. Han, H., Z. He and Y. Zheng, 1999. Chemiluminescence determination of tetracyclines using a tris (2, 2'-bipyridine) ruthenium (II) and potassium permanganate system. Anal. Sci., 15: 467-470. DOI: 10.2116/analsci.15.467
17. Palahran, S., T. Charoenaraks, N. Wangfuengkanagul, K. Grudpan and O. Chailapakul, 2003. Flow injection analysis of tetracycline in pharmaceutical formulation with pulsed amperometric detection Anal. Chim. Acta, 449: 191-197. DOI: 10.1016/S0003-2670(03)00948-6

18. Tanase, I., I. David, G. Radu, E. Iorgulescu and V. Magearu. 1996. Optimised electroanalysis of tetracycline by alternating current polarography. Analusis, 24: 281-284. http://cat.inist.fr/?aModele=afficheN\&cpsidt=2500708

19. Kazemifard, A.G. and D.E. Morre, 1997. Evaluation of amperometric detection for the liquid-chromatographic determination of tetracycline antibiotics and their common contaminants in pharmaceutical formulations. J. Pharm. Biomed. Anal., 16: 689-696. DOI: 10.1016/S0731-7085(97)00089-7

20. Oungpipat, W., P.W. Alexander and P. Southwell-Keely, 1995. Flow injection detection of tetracyclines by electrocatalytic oxidation at a nickel-modified glassy carbon electrode. Analyst, 120: 1559-1565. DOI: 10.1039/AN9952001559

21. Abdel-Kahlek, M.M. and M.S. Mahrous, 1983. Spectrophotometric determination of tetracyclines and cephalosporins with ammonium vanadate. Talanta, 30: 792-797. DOI: 10.1016/00399140(83)80181-7

22. Suha, U., 1989. Colorimetric determination of tetracycline derivatives in pharmaceutical preparations. J. Assoc. Anal. Chem., 72: 242-244. http://www.ncbi.nlm.nih.gov/pubmed/2708271

23. Emara, K.M., H.F. Askel and G.A. Saleh, 1991. Spectrophotometric determination of tetracycline and oxytetracycline in pharmaceutical preparations. Talanta, 38: 1219-1221. DOI: 10.1016/00399140(91)80095-H

24. Jelikie-Stankov, M., D. Veselinovic, D. Maslesev and Z. Radovic, 1989. Spectrophotometric determination of oxytetracycline in pharmaceutical preparations using sodium molybdate as analytical reagent. J. Pharm. Biomed. Anal., 7: 1565-1570. DOI: 10.1016/0731-7085(89)80166-9

25. Leming, D., X. Qingqin and Y. Jianmei, 2003. Fluorescence spectroscopy determination of fluoroquinolones by charge-transfer reaction. J. Pharm. Biomed. Anal., 33: 693-698. DOI: 10.1016/S0731-7085(03)00365-0

26. Mostafa, S., M. El-Sadek and E. AwadAlla, 2002. Spectrophotometric determination of ciprofloxacin, enrofloxacin and pefloxacin through charge transfer complex formation. J. Pharm. Biomed. Anal., 27: 133-142. DOI: 10.1016/S07317085(03)00365-0 
27. Saleh, G.A., H.F. Askel, M.F. Ramadan and M.A. Omar, 2001. Use of charge-transfer complexation in the spectrophotometric analysis of certain cephalosporins. Talanta, 54: 1205-1215. DOI: 10.1016/S0039-9140(01)00409-X

28. Saleh, G.A., H.F. Askel, I.A. Darwish and A.A. El Shorbagi. 2003. Spectroscopic analytical study for the charge-transfer complexation of certain cephalosporins with chloranilic acid. Anal. Sci., 19: 28-2871. DOI: 10.2116/analsci.19.281

29. El-Zeany, B.A., A.A. Moustafa and N.F. Farid, 2003. Determination of imipramine in presence of iminodibenzyl and in pharmaceutical dosage form. J. Pharm. Biomed. Anal., 33: 775-782. DOI: 10.1016/S0731-7085(03)00234-6

30. Ogoda Onah, J. and J. Eromi Odeiani, 2002. Simultaneous spectrophotometric determination of sulfadoxine and pyrimethamine in pharmaceutical formulations. J. Pharm. Biomed. Anal., 30: 851-857. DOI: 10.1016/S0731-7085(02)00361-8

31. Khashaba, P.Y., S.R. El-Shabouri, K.E. Emara and A.M. Mohamed, 2000. Analysis of some antifungal drugs by spectrophotometric and spectrofluorimetric methods in different pharmaceutical dosage forms. J. Pharm. Biomed. Anal., 22: 363-376. DOI: 10.1016/S0731-7085(99)00280-0

32. El-Reis, M.A., F.M. Abou-Attia and S.A. Ibrahim, 2000. AAS and spectrophotometric determination of propranolol $\mathrm{HCl}$ and metoprolol tartrate. J. Pharm. Biomed. Anal., 24: 179-187. DOI: 10.1016/S0731-7085(00)00408-8
33. Schwarzenbach, G. and H. Suter, 1941. Helv chim. Acta, 24: 617-623. DOI: 10.1002/hlca.19410240183

34. Inczedy, J., 1976. Analytical Application of Complex Equilibria. 1st Edn., Akademiai Kiado, Budapest, pp: 101.

35. Gatti, R., V. Cavrini, B. Balboni and P. Roveri, 1985. Colorimetric assay for methimazole in tablet formulations using the 2, 6-dichloroquinone chloroimide reagent. Farmaco, 40: 71-76. http://www.ncbi.nlm.nih.gov/pubmed/3996559

36. Daniels, F., 1970. Experimental Physical Chemistry. 7th Edn., McGraw-Hill Bood Co., USA., pp: 123-147.

37. Calcut, R and R. Boddy. 1983. Statistics for Analytical Chemists. 5th Edn., Chapman and Hall, London, ISBN: 041223730X, pp: 76-93. 